Article

\title{
Evaluation of Health-Habits with the S.M.A.R.T. Questionnaire: An Observational Study
}

\author{
Francesco Vincenzo Ferraro ${ }^{1, *(1)}$, Ferdinando Ivano Ambra ${ }^{2}(1)$ and Maria Luisa Iavarone ${ }^{2}$ \\ 1 Orthopaedic Research Institute, Faculty of Health and Social Science, Bournemouth University, \\ Dorset BH12 5BB, UK \\ 2 Dipartimento di Scienze Motorie e del Benessere, Università degli Studi di Napoli Parthenope, \\ 80133 Naples, Italy; ivano.ambra@uniparthenope.it (F.I.A.); marialuisa.iavarone@uniparthenope.it (M.L.I.) \\ * Correspondence: fferraro@bournemouth.ac.uk
}

Received: 16 September 2020; Accepted: 13 October 2020; Published: 16 October 2020

\begin{abstract}
The civil education approach uses sports practise as a preventive intervention to increase self-awareness and to help modulate emotion in adolescents. Indeed, sports participation results in a better quality of life, more favourable cardio-metabolic and sleeping profiles and a healthier body composition. Adolescents involved in sport activities also report a higher level of social and emotional skills, and reduced mental health distress. However, the Italian school's program provides only two hours weekly of physical education, with lack of options and participation. In alignment with the civil educational approach, the research team aims to develop a predictive sport, movement, eating habits, relationships and technologies (S.M.A.R.T.) questionnaire to identify the youths that present a higher risk of delinquency. The following research aims to explore preliminary data from 501 adolescents completing the S.M.A.R.T. The results show that the female group $(n=260)$ was healthier than the male group $(\mathrm{n}=241)$; particularly, the female group demonstrated a higher level of self-awareness in the use of technologies $(p<0.05)$. Our results produce the first data set on a cohort of young adolescents in Italy using the S.M.A.R.T. questionnaire. The questionnaire possesses a high response rate and should now be implemented towards validation.
\end{abstract}

Keywords: pedagogy; sport science; transdisciplinary; childhood learning; technologies; relationship; civil education approach; risks; predictive index; education

\section{Introduction}

According to the World Health Organization (WHO), a healthy lifestyle is a way of living that lowers the risks of being seriously ill [1]. Participating in sport activities during childhood has been supported as a health promotion strategy. Youths (age range between 5 and 17) should accumulate at least $60 \mathrm{~min}$ of moderate to vigorous physical activity daily. In particular, evidence-based research reported that sport participation results in a better quality of life [2], more favourable cardio-metabolic and sleeping profiles [3] and healthier body composition [4]. Adolescents involved in sport activities also reported higher levels of social and emotional skills (such as self-esteem and greater social skills with peers) and reduced risks of mental health distress [5]. On the contrary, lack of physical activities has been associated with smoking and excessive alcohol consumption [6]. While the relationship between unhealthy behaviour and intensity of mobile phone use is still under discussion [7], a recent meta-analysis has shown a strong association between social network consumption and mental illness, in particular with relation to alcohol abuse, disordered eating domains [8] and with distorted self-presentation caused by digital egocentrism and digital narcissism [9] which produces sexualised behaviours in very young adolescents [10]. Recently neuroscience contributions have demonstrated that social and emotional factors influence adolescent's cognitive abilities and academic achievements [11], 
informing educational practise of the neuro-mechanisms produced by social and emotional effects on learning [12]. Those neuro-mechanisms can be enhanced by sports participation, particularly in situations where adolescent deviance is due to a context of poor cultural development and social exclusion [13]. It is rational to conceive then that adolescent delinquency is a direct result of educational lack and absence of self-awareness [14]. The civil education approach uses sports practise as a preventive intervention to increase self-awareness and responsibility, and to help modulate emotion in adolescents at risk [15]. Briefly, transformative arts (such as dance) have been successfully used as educational practise with adolescents via the Responsible Adults for a United Territory against the Risk (ARTUR; www.associazioneartur.org) Association [16]. In Italy, the school's program provides only two hours a week of physical education, where students can practise sports or learn about sport-related science [17]. However, the recent report (2018) of The Italian National Statics Institute reported that only $50 \%$ of adolescents practise sports regularly [18]. This means there is an evident lack of physical activity options for half of all Italian adolescents. In alignment with the civil educational approach, the research team aims to develop a predictive research tool that can help identify the adolescents that are at a higher risk of unhealthy behaviours; a tool that can be used to create a quantitative index and predict the deviance risk in adolescents starting from sports participation [19]. We believe that such a tool can be of help to the civil education approach if adopted by institutions [20] (e.g., families and schools) to monitor the risks of unhealthy behaviours [21]. The purpose of this manuscript is to report the first use of the sport, movement, eating habits, relationships and technologies (S.M.A.R.T.) questionnaire in a cohort of young adolescents.

\section{Materials and Methods}

\subsection{General Design}

This observational, exploratory pilot study is the first to report the results of a group of adolescents completing the S.M.A.R.T. questionnaire. S.M.A.R.T. is the acronym of the Italian words for sport, movement (trsl. Movimento), eating habits (trsl. Alimentazione), relationships (trls. Relazioni) and technologies (trsl. Tecnologie) developed by the international transdisciplinary collaboration of researchers from different fields at University of Naples Parthenope (ITA) and Bournemouth University (UK) supervised by Prof. M.L. Iavarone. The questionnaire consists of 5 sub-questionnaires evaluating 5 sub-domains: (i) the sub-scale "sport" evaluates motivation, involvement and participation in sport activities (such as football, basket and tennis); (ii) "movement" explores active lifestyle attitude (including recreational activities such as horse riding and street football); (iii) "eating habits" concerns attitude with food and consumption of junk food; (iv) "relationships" inquires into interactive social behaviours and social skills with peers; and (v) "technologies" explores critical and conscious use of technologies. Each domain contains a different number of questions that present multiple answers with a score from 0 to 3 ( 0 being the lowest and 3 the highest score); a higher score indicates healthier habits whereas a lower score indicates unhealthy habits. The score in each domain is given by the mean of all the answers and the total score is calculated by summing each domain, (Table 1). Preliminary structure and validation of the questionnaire have been presented at the Well-being in Education Systems Conference [19].

Table 1. The sub-domains of the sport, movement, eating habits, relationships and technologies (S.M.A.R.T.) questionnaire, what they evaluate and the number of questions in each.

\begin{tabular}{cccc}
\hline & Sub-Domain & Evaluate & Number of Questions \\
\hline $\mathbf{S}$ & Sport & Motivation and participation in sport activity & 10 \\
$\mathbf{M}$ & Movement & Active lifestyle attitude & 7 \\
$\mathbf{A}$ & Eating Habits & Healthy lifestyle & 14 \\
$\mathbf{R}$ & Relationships & Social behaviours with peers & 6 \\
$\mathbf{T}$ & Technologies & Critical and conscious use of technologies & 9 \\
\hline
\end{tabular}




\subsection{Participant Characteristics}

A group of 501 adolescents (260 F, $241 \mathrm{M}$; age range 10 to 15 years old) from a sample of 539 completed the S.M.A.R.T. questionnaire, between 2017 and 2018, in four schools from Naples (Italy) (Figure 1). To include a broad sample of adolescents, no-specific inclusion/exclusion criteria were selected. All participants completed the questionnaire on their own, at school, without strict supervision. Enough time to answer all the questions was given (20 to $30 \mathrm{~min}$ ). Data were anonymised and collected according to the guidelines of the 1975 Declaration of Helsinki, revised in 2013.

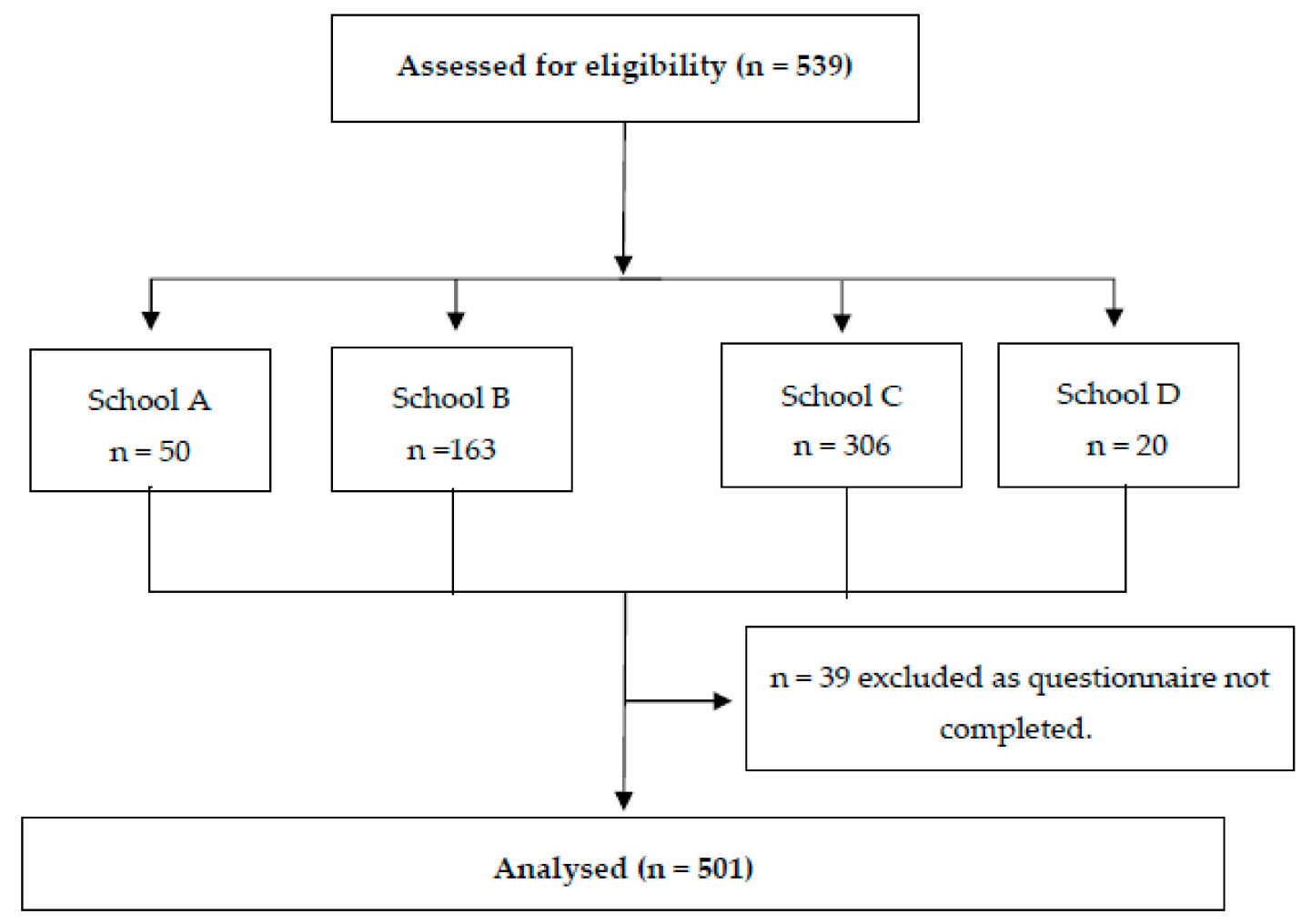

Figure 1. Flow diagram displaying participants' pathways through the study.

\subsection{Data Analysis}

The aim of the observational, pilot study was to explore the first use of the S.M.A.R.T. questionnaire in a cohort of young adolescents (10 to 15 years old). Data were grouped by age range (10-12 and 13-15 years old) and by gender. Test of normality (i.e., Shapiro-Wilk) showed that the data were not normally distributed; therefore, to report whether there was any effect of age and gender in participants responses, a Mann-Whitney test was completed. Additionally, to identify potential associations within S.M.A.R.T. sub-domains, a Pearson correlation was also carried out. The threshold for statistical significance was determined a priori as $p \leq 0.05$. Data are reported with mean and standard deviation. The analysis was completed with software IBM SPSS 26.

\section{Results}

A total of $93 \%$ of questionnaires (501 out of 539) were successfully completed. The overall S.M.A.R.T score was $9.1 \pm 1.2$ (max. possible score $=15$ ). Mann-Whitney analysis showed that the female group was significantly healthier than the male group $(p=0.003)$, whilst comparison between younger and older cohort was not significant $(p=0.7)$, (Table 2, Figure 2). 
Table 2. Overall S.M.A.R.T. score and sub-domains analysis between gender and age groups.

\begin{tabular}{cccccc}
\hline S.M.A.R.T. & $\begin{array}{c}\text { Total } \mathbf{( n = 5 0 1 )} \\
\mathbf{9 . 1} \pm \mathbf{1 . 2}\end{array}$ & $\begin{array}{c}\text { Male }(\mathbf{n}=\mathbf{2 4 1}) \\
\mathbf{8 . 9} \pm \mathbf{1 . 2}\end{array}$ & $\begin{array}{c}\text { Female }(\mathbf{n}=\mathbf{2 6 0}) \\
\mathbf{9 . 2} \pm \mathbf{1 . 2} * *\end{array}$ & $\begin{array}{c}\mathbf{1 0}-\mathbf{1 2}(\mathbf{n}=\mathbf{3 2 7}) \\
\mathbf{9 . 1} \pm \mathbf{1 . 2}\end{array}$ & $\begin{array}{c}\mathbf{1 3 - 1 5}(\mathbf{n}=\mathbf{1 7 4}) \\
\mathbf{9 . 1} \pm \mathbf{1 . 2}\end{array}$ \\
\hline Sub-Domain & & & & & \\
Sport & $2.2 \pm 0.5$ & $2.1 \pm 0.4$ & $2.2 \pm 0.5$ & $2.2 \pm 0.4$ & $2.2 \pm 0.5$ \\
Movement & $1.8 \pm 0.4$ & $1.7 \pm 0.4$ & $1.8 \pm 0.4$ & $1.7 \pm 0.4$ & $1.8 \pm 0.4$ \\
Eating Habits & $1.9 \pm 0.4$ & $1.8 \pm 0.4$ & $1.9 \pm 0.4$ & $1.9 \pm 0.4 *$ & $1.8 \pm 0.4$ \\
Relationships & $1.9 \pm 0.5$ & $1.8 \pm 0.4$ & $1.8 \pm 0.5$ & $1.8 \pm 0.5$ & $1.9 \pm 0.4^{* *}$ \\
Technologies & $1.4 \pm 0.4$ & $1.3 \pm 0.4$ & $1.5 \pm 0.4^{* *}$ & $1.5 \pm 0.4$ & $1.4 \pm 0.4$ \\
\hline
\end{tabular}

Data are reported as mean \pm standard deviation. ${ }^{* *}$ Groups significant different with $p<0.01$.

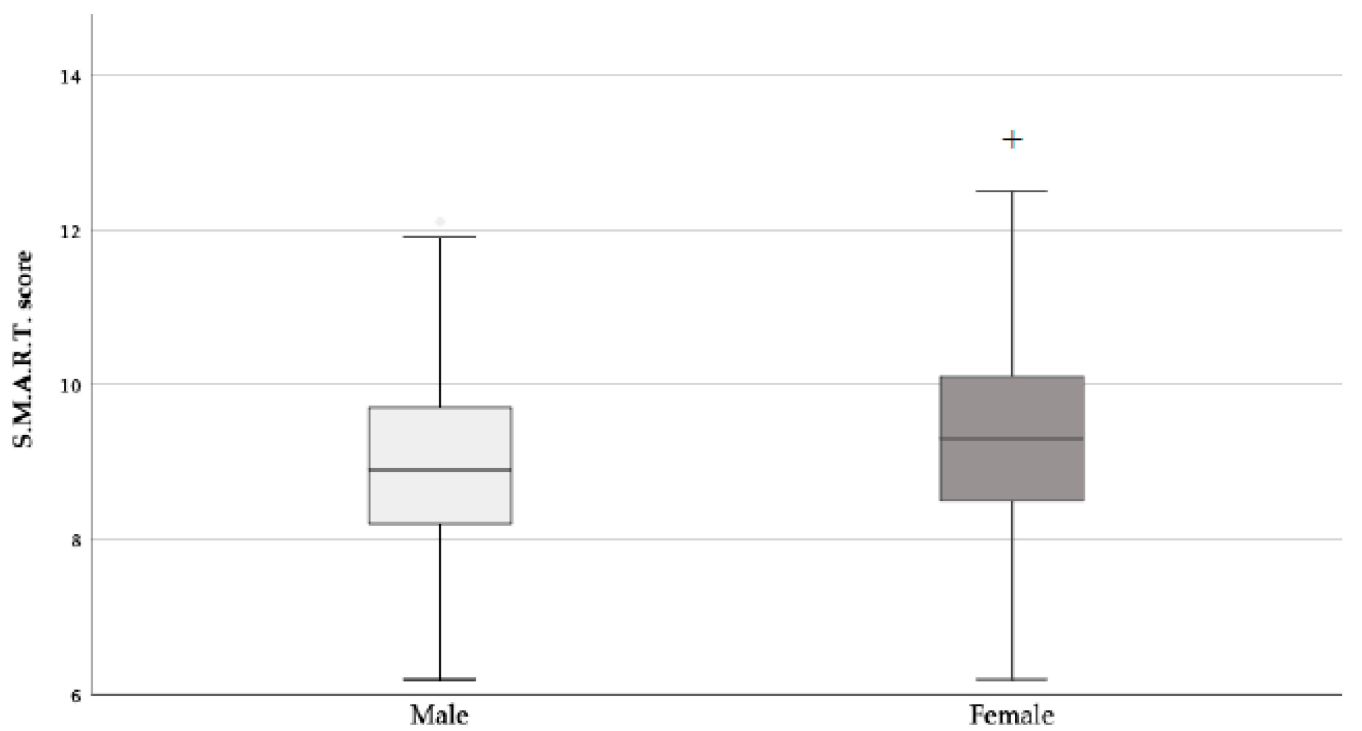

Figure 2. Analysis of means showed that the female group $(n=260$; Total S.M.A.R.T. score $=9.2)$ was significantly $(p<0.01)$ healthier that the male group $(n=241$; Total S.M.A.R.T. score $=8.2)$.

\subsection{Sub-Domains}

Analysis of sub-domains sport and movement showed no significant differences between genders $(p=0.4 ; p=0.5$, respectively) and ages $(p=0.8 ; p=0.4$ respectively). A comprehensive description of the activities and the sports played by our cohort are fully reported in Table 3.

Table 3. Percentages of sports participation in 501 adolescents aged between 10 to 15 years old, in the southern region of Italy (Naples).

\begin{tabular}{cc}
\hline List of Sports & Percentage \\
\hline Volleyball & $27.8 \%$ \\
Football & $21.5 \%$ \\
Dancing & $9.8 \%$ \\
Basket & $8.6 \%$ \\
Artistic gymnastics & $5.4 \%$ \\
No practising any sport & $5.1 \%$ \\
Swimming & $4.8 \%$ \\
Taekwondo & $4.3 \%$ \\
Rhythmic gymnastics & $3.8 \%$ \\
Tennis & $2.9 \%$ \\
Gym membership & $1.5 \%$ \\
Rugby & $1.5 \%$ \\
Athletics & $1.0 \%$ \\
Karate, Kickboxing & $0.8 \%$ \\
Fencing, Fit box, Horse riding, Rowing & $0.6 \%$ \\
Martial arts, Table tennis, Water polo & $0.4 \%$ \\
\hline Hockey, Hydro-bike, Mixed martial arts, Judo, Pilates, Squash & $0.2 \%$
\end{tabular}


Analysis of sub-domain eating habits showed significant differences in the age groups $(p=0.007)$ whilst genders were not significantly different $(p=0.2)$, (Figure 3 ). Analysis of sub-domain relationships showed significant differences in the age groups $(p=0.001)$ whilst genders were not significantly different $(p=0.1)$, (Figure 4).

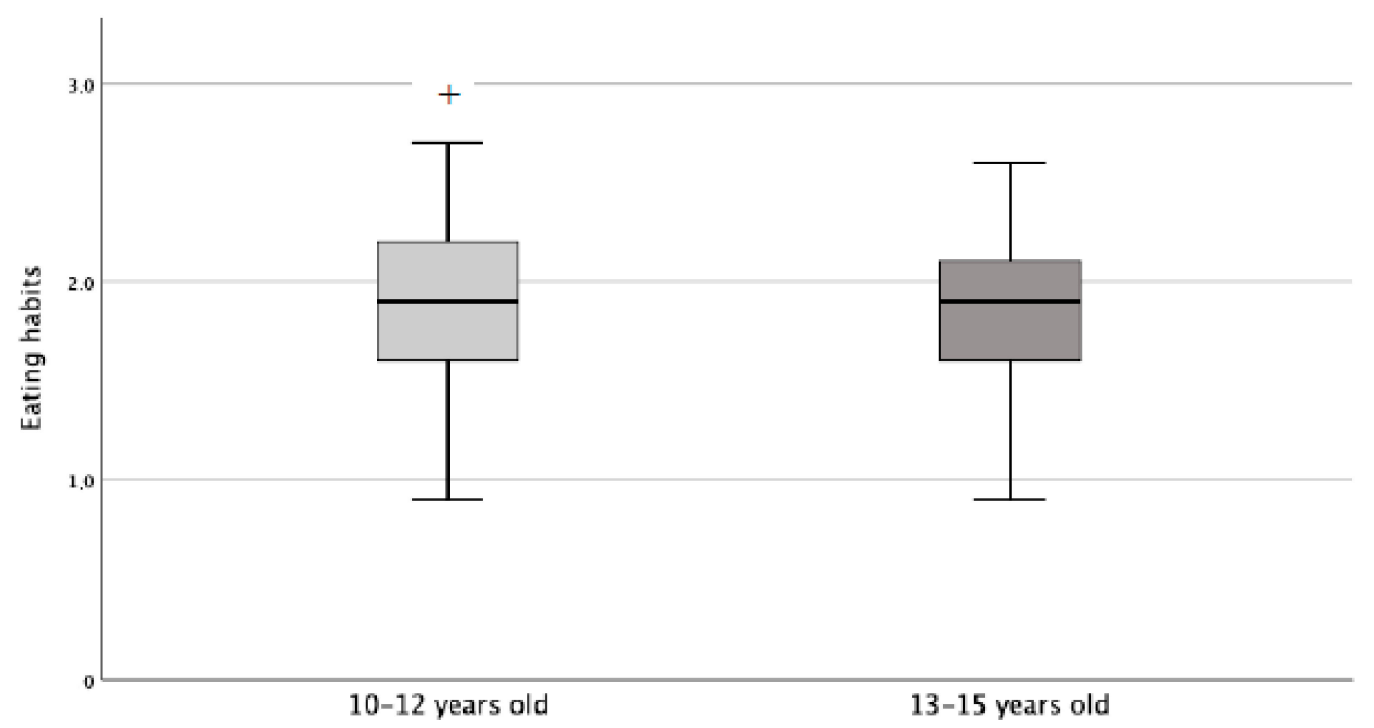

Figure 3. Analysis of means of the sub-domain eating habits showed that the older population ( $\mathrm{n}=174$; Total score $=1.8)$ is less healthy $(p<0.01)$ that the younger population $(n=237$; Total score $=1.9)$.

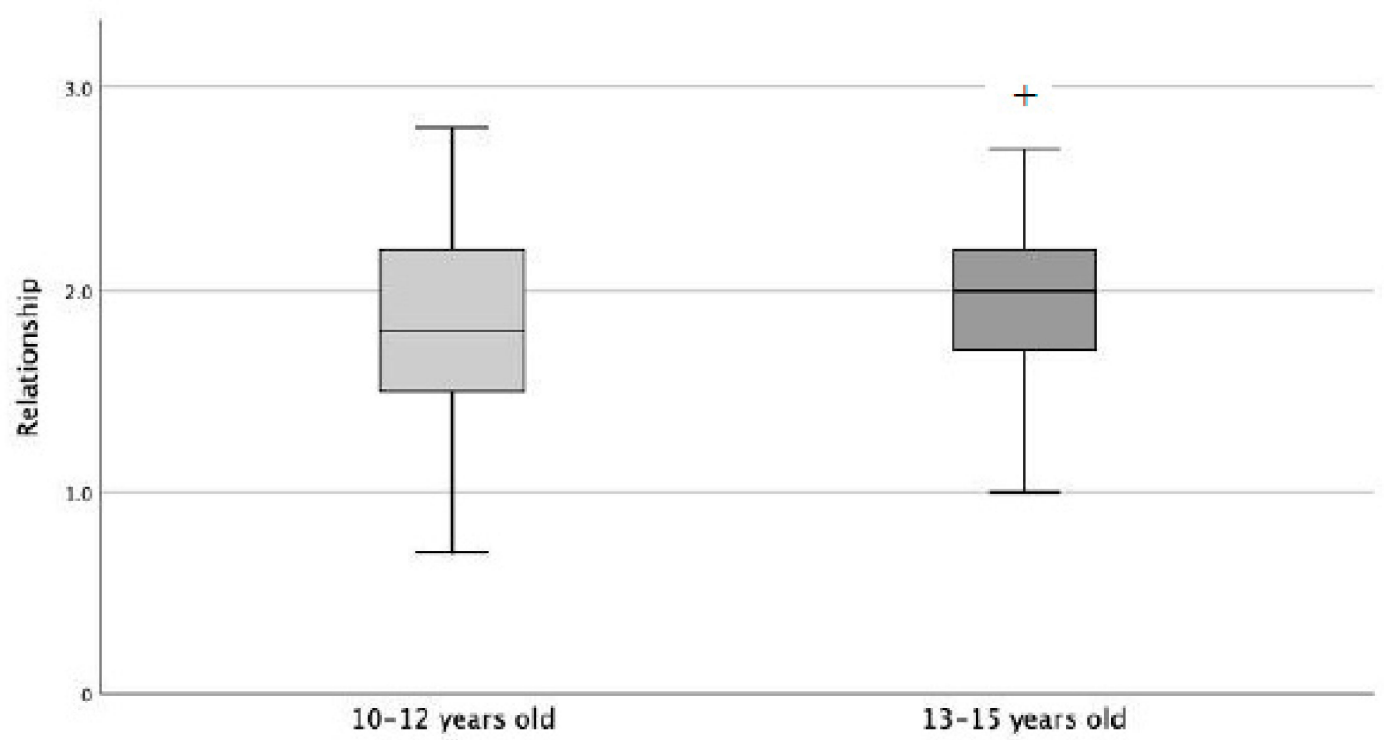

Figure 4. Analysis of means of the sub-domain relationships showed that the older population $(\mathrm{n}=174$; Total score $=1.9)$ is healthier $(p<0.01)$ that the younger population $(n=237$; Total score $=1.8)$.

Analysis of sub-domain technologies showed significant gender differences $(p=0.001)$, whilst age groups were not significant ( $p=0.07)$, (Figure 5). 


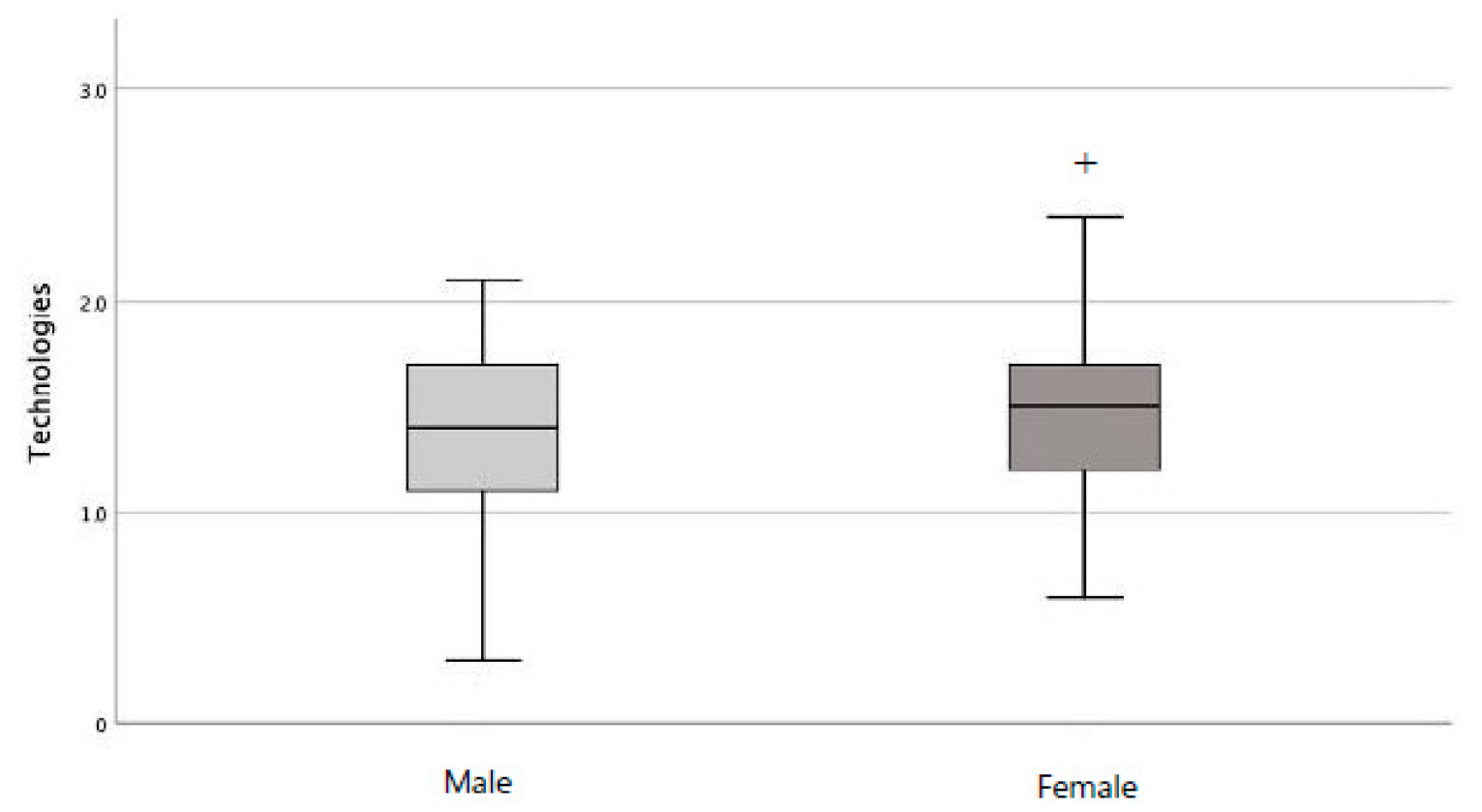

Figure 5. Analysis of mean of the sub-domain technologies showed that the female group ( $\mathrm{n}=260$; Total score $=1.5)$ is healthier $(p<0.01)$ than the male group $(\mathrm{n}=241$; Total score $=1.3)$.

\subsection{Associations between S.M.A.R.T. Sub-Domains}

Pearson correlation showed significant associations between sport and technologies $(p=0.002)$, and eating habits and technologies $(p=0.0001)$, with a healthy use of the technologies is associated with higher sports participation and healthier eating habits. Data are reported in Table 4.

Table 4. Sub-domain correlation analysis.

\begin{tabular}{ccccc}
\hline Sub-Domains & Sport & Movement & Eating Habit & Relationship \\
\hline Sport & & & & \\
Movement & 0.08 & & & \\
Eating Habits & 0.1 & 0.2 & & \\
Relationships & 0.09 & 0.2 & 0.06 & 0.07 \\
Technologies & $0.002 * *$ & 0.1 & 0.0001 ** & \\
\hline Pearson correlation between each S.M.A.R.T. sub-domain; & ** correlation is significant with $p<0.01$.
\end{tabular}

\section{Discussion}

This is the first research to explore the use of the S.M.A.R.T. questionnaire. The research aims to observe and report the results of a questionnaire that is undergoing implementation by a transdisciplinary collaboration between the University of Naples Parthenope and Bournemouth University. The research team's final aim is to produce a novel research tool that can help to identify the adolescents that are at a higher risk of delinquency, and that can be used to create a quantitative index and predict the deviance risk starting from sports participation. The research team believes that such a tool can be beneficial for the civil education approach [13] if adopted by institutions (e.g., families and schools) to monitor the risks of misbehavior. In particular, the questionnaire can be adopted by teachers to explore the prevalence of violence and aggression in adolescents [22] in light of recent reports about physical assault, verbal threats, and aggressive damage of property, directed against adults and peers [23]. Our observational study reported that the questionnaire, presented without supervision, was successfully completed by $93 \%$ of the participants, which indicated a high response rate, considering the young age of our cohort [24]. Results showed that the female group was healthier than the male group, particularly in the use of technologies. It appears that the female 
group had lower consumption of technologies and a higher self-awareness of the information that can be transferred over social media. However, it is important to consider these results in light with the potential influence of parental control [25] over the female population. A recent meta-analysis reported that gender-differentiated parental control in child behaviour is driven by gender's stereotypes [26] and it might explain why the female group resulted in being more aware of technologies than the male group. Moreover, the results also showed that the older cohort was less aware of its eating habits but more aware of the importance of relationship with peers. These results might indicate the potential role of parenting control on eating habits which decrease when entering adolescence. These outcomes are extremely concerning since the consumption of high calories junk-food can produce a direct negative effect on brain function and behavioural control [27]. A better understanding of adolescence and dietary decision making is essential in the civil education approach and can help in producing effective intervention strategies to prevent unhealthy behaviours [13]. These strategies can also apply to clinicians and health-care professional for reducing long-term costs associated with obesity [28]. These results should be also considered in light of recent association between stress in parents and child obesity [29]. The sub-domain relationship showed that the older population is able to spend high-quality time with friends outside schools' hours. The impact of relationship with peers is extremely important in adolescents, particularly in situations of high psychological stress [30], where events such as bullying can lead to misconducting behaviours [31] and poor mental health [32]. These aspect have to be considered by teachers as the upcoming generation of authentic digital natives defined as hyper-cognitive generation [33] is able to interact with peers via social media platform (e.g., TikTok) which are most of the time inaccessible by the older generations. Considering that the S.M.A.R.T. questionnaire aims to became a predictive risk tool in situations where adolescents are at risk of unhealthy behaviour, our results seem extremely positive, underling the importance of further empirical study in the analysis of adolescent peers' relations. In particular, further study can adopt the S.M.A.R.T. questionnaire as a multidisciplinary risks assessment tool in situations where students are more likely to be exposed to delinquency [34]. Concluding, analysis of relationships between sub-domains indicate a strong relationship between the use of technologies with sport participations and eating habits. A healthier use of technologies is associated with higher sport participation and healthier eating habits. Our results are in accordance with previous finding and WHO guidelines reporting that sports participation results in a higher quality of life [2], more favourable cardio-metabolic and sleeping profiles [3] and healthier body composition [4]. Additionally, adolescents involved in sport activities reported a higher level of social and emotional skills and reduced risk for mental health distress [5]. Considering that the adolescents who are at risk for committing violence possess multiple demographic co-occurring aspects, including social, cultural, gender, age, ethnicity, past-victimization, and drug or alcohol use among many other factors that contribute to violence [35], it is necessary for the research community to produce predictive questionnaires that can prevent unrecoverable criminal behaviours [16].

\section{Conclusions and Limitations}

The S.M.A.R.T. questionnaire can help the civil education approach if used by institutions (e.g., families and schools) to monitor the risks of unhealthy behaviours. This study reports the first use of the S.M.A.R.T. questionnaire that is being developed by an international transdisciplinary collaboration between the University of Naples Parthenope (ITA) and the University of Bournemouth (UK) under the supervision of Prof. M.L. Iavarone. Our results produced the first data set on a cohort of young adolescents in the southern region of Italy (Naples) and show that the questionnaire possesses a high response rate and should now be implemented for further research. The next study should translate and validate the questionnaire so that it can be used by other researchers in different setting. Further research is needed in the relationship between emotional factors and social skills with the sports habits of adolescents. Additionally, future studies should adopt the S.M.A.R.T. questionnaire in 
situations of high risk for adolescents, introducing transformative sport intervention (such as dance) to monitor their progression (e.g., before and after intervention analysis).

The study possesses several limitations. It lacks information that can predict the parental control on activities such as technologies consumption or eating habits and the relationship with adolescents and parents or tutors. Further research should monitor this by introducing additional questionnaires for the parents or tutors. The study was not powerful enough for a validation analysis, and with the limitation of having to use the questionnaire in a specific region the research team was unable to report details about the factor analysis. However, the manuscript aims to present the first results of a predictive questionnaire which is undergoing implementation and will be validated in the upcoming future using a robust interpretivist approach and mixed methods. Translation of the questionnaire needs validation and correlation analysis also to make sure that the questions match between Italian and English and the interpretation from the perspective of the adolescents is the same. Therefore, the research team will aim to publish the questionnaire in the upcoming future along with a robust statistical analysis that reports factors of validation, reliability and accuracy for each question.

Author Contributions: Conceptualization, F.V.F. and F.I.A.; methodology, F.V.F. and F.I.A.; validation, F.V.F., F.I.A. and M.L.I.; formal analysis, F.V.F.; investigation, F.I.A.; resources, F.V.F.; data curation, F.V.F.; writing-original draft preparation, F.V.F.; writing - review and editing, M.L.I. and F.I.A.; visualization, F.V.F.; supervision, M.L.I.; project administration, F.I.A.; funding acquisition, F.V.F., F.I.A. and M.L.I. All authors have read and agreed to the published version of the manuscript.

Funding: This research received no external funding.

Acknowledgments: The authors would like to thank all the participants that took their time to take part in the research.

Conflicts of Interest: The authors declare no conflict of interest.

\section{References}

1. WHO. Healthy Living: What is a Healthy Lifestyle? WHO Regional Office for Europe: Copenhagen, Denmark, 1999.

2. Vella, S.A.; Gardner, L.; Kemp, B.J.; Swann, C. Health-related quality of life as a longitudinal mediator of the relationship between participation in organised sports and adiposity among young people. Prev. Med. Rep. 2018, 12, 66-70. [CrossRef] [PubMed]

3. Hjorth, M.F.; Chaput, J.-P.; Damsgaard, C.T.; Dalskov, S.-M.; Andersen, R.; Astrup, A.; Michaelsen, K.F.; Tetens, I.; Ritz, C.; Sjödin, A. Low Physical Activity Level and Short Sleep Duration Are Associated with an Increased Cardio-Metabolic Risk Profile: A Longitudinal Study in 8-11 Year Old Danish Children. PLoS ONE 2014, 9, e104677. [CrossRef] [PubMed]

4. Vella, S.A.; Gardner, L.; Kemp, B.; Schweickle, M.J; Cliff, D.P. Sports Participation, Health Behaviours, and Body Fat during Childhood and Early Adolescence: A Multiple Mediation. J. Sci. Med. Sport 2019, 22, 1324-1329. [CrossRef] [PubMed]

5. Eime, R.M.; Young, J.A.; Harvey, J.T.; Charity, M.J.; Payne, W.R. A systematic review of the psychological and social benefits of participation in sport for children and adolescents: Informing development of a conceptual model of health through sport. Int. J. Behav. Nutr. Phys. Act. 2013, 10, 98. [CrossRef]

6. Kang, K.; Sung, J.; Kim, C.-Y. High Risk Groups in Health Behavior Defined by Clustering of Smoking, Alcohol, and Exercise Habits: National Heath and Nutrition Examination Survey. J. Prev. Med. Public Health 2010, 43, 73-83. [CrossRef]

7. Koivusilta, L.K.; Tomi, L.; Arja, R.R. Intensity of mobile phone use and health compromising behaviours-How is information and communication technology connected to health-related lifestyle in adolescence? J. Adolesc. 2005, 28, 35-47. [CrossRef]

8. Frost, R.L.; Rickwood, D.J. A systematic review of the mental health outcomes associated with Facebook use. Comput. Hum. Behav. 2017, 76, 576-600. [CrossRef]

9. Hernández, M.P.; De La Barrera, U.; Schoeps, K.; Montoya-Castilla, I. Psychological Risk Factors that Predict Social Networking and Internet Addiction in Adolescents. Int. J. Environ. Res. Public Health 2020, 17, 4598. [CrossRef] 
10. Sarabia, I.; Estévez, A. Sexualized behaviors on Facebook. Comput. Hum. Behav. 2016, 61, 219-226. [CrossRef]

11. Immordino-Yang, M.H. Emotion, Sociality, and the Brain's Default Mode Network. Policy Insights Behav. Brain Sci. 2016, 3, 211-219. [CrossRef]

12. Schmidt, S.J. What Does Emotion Have to Do with Learning? Everything! J. Food Sci. Educ. 2017, 16, $64-66$. [CrossRef]

13. Shucksmith, M. Young People and Social Exclusion in Rural Areas. Sociol. Rural. 2004, 44, 43-59. [CrossRef]

14. Pierluigi, M.; Maria, M.; Luigina, G.; Teresa, G.R.; Maria, F.; Roberto, S.; Milena, C.C.; Lucia, I.L.; Massimiliano, F. Landascape education as italian contribution to the implementation of the agenda 2030. Pedagog. Oggi 2018, 1, 9-11.

15. Iavarone, M.L. Curare i margini. Riprendersi il senso dell'educazione per prevenire il rischio. Ann. Online Didatt. Form. Docente 2019, 11, 1-5.

16. Iavarone, M.L.; Trocchia, N. Il Coraggio delle Cicatrici: Storia di Mio Figlio Arturo e della Nostra Lotta; Utet: Torino, Italy, 2020; ISBN 8851179611.

17. Viscione, I.; Invernizzi, P.L.; Raiola, G. Physical education in secondary higher school. J. Hum. Sport Exerc. 2019. [CrossRef]

18. ISTAT. Aspetti Della vita Quotidiana: Persone di 15-34 Anni-Serie Storica. 2018. Available online: http://dati-giovani.istat.it/Index.aspx?QueryId=15572 (accessed on 25 March 2018).

19. Ambra, F.I.; Ferraro, F.V.; Ferra, V.; Basile, S.; Girardi, F.; Menafro, M.; Iavarone, M.L.; Napoli, A.S.L.A.; Centro, N.O.D.N. Impact of Sport Training on Healthy Behavior in a Group of 108 Adolescents: A Pilot Study Using Smart Questionnaire. Well-being in Education Systems 43. Available online: https://www2.supsi.ch/ cms/wellbeing/wp-content/uploads/sites/28/2019/11/2ndEdition_BookOfAbstract.pdf\#page=56 (accessed on 13 October 2020).

20. Iavarone, M.L. Alta Formazione per lo Sviluppo Educativo Locale; Liguori Editore: Napoli, Italy, 2009.

21. Iavarone, M.L.; Iavarone, T. Pedagogia del benessere. Per una Professionalità Educativa in Ambito Psico-SocioSanitario; Franco Angeli: Milano, Italy, 2004.

22. McMahon, S.D.; Reaves, S.; McConnell, E.A.; Peist, E.; Ruiz, L. The Ecology of Teachers' Experiences with Violence and Lack of Administrative Support. Am. J. Community Psychol. 2017, 60, 502-515. [CrossRef]

23. Moon, B.; McCluskey, J. An Exploratory Study of Violence and Aggression against Teachers in Middle and High Schools: Prevalence, Predictors, and Negative Consequences. J. Sch. Violence 2018, 19, 122-137. [CrossRef]

24. Champion, D.J.; Sear, A.M. Questionnaire Response Rate: A Methodological Analysis. Soc. Forces 1969, 47, 335-339. [CrossRef]

25. Landry, M.; Turner, M.M.; Vyas, A.; Wood, S.F.; Broom, M.; Allen, N. Social Media and Sexual Behavior Among Adolescents: Is there a link? JMIR Public Health Surveill. 2017, 3, e28. [CrossRef]

26. Endendijk, J.J.; Groeneveld, M.G.; Bakermans-Kranenburg, M.J.; Mesman, J. Gender-Differentiated Parenting Revisited: Meta-Analysis Reveals Very Few Differences in Parental Control of Boys and Girls. PLoS ONE 2016, 11, e0159193. [CrossRef]

27. Malik, V.; Pan, A.; Willett, W.C.; Hu, F.B. Sugar-sweetened beverages and weight gain in children and adults: A systematic review and meta-analysis. Am. J. Clin. Nutr. 2013, 98, 1084-1102. [CrossRef] [PubMed]

28. Lowe, C.J.; Morton, J.B.; Reichelt, A.C. Adolescent obesity and dietary decision making-A brain-health perspective. Lancet Child Adolesc. Health 2020, 4, 388-396. [CrossRef]

29. Parks, E.P.; Kumanyika, S.; Moore, R.H.; Stettler, N.; Wrotniak, B.H.; Kazak, A. Influence of Stress in Parents on Child Obesity and Related Behaviors. Pediatrics 2012, 130, e1096-e1104. [CrossRef]

30. Thoits, P.A. Stress and Health: Major Findings and Policy Implications. J. Health Soc. Behav. 2010, 51, S41-S53. [CrossRef]

31. Miura, H.; Fuchigami, Y. Influence of maltreatment, bullying, and neurocognitive impairment on recidivism in adolescents with conduct disorder: A 3-Year prospective study. Appl. Neuropsychol. Child. 2020, 1-10. [CrossRef]

32. Pitman, A.; Osborn, D.; King, M.; Erlangsen, A. Effects of suicide bereavement on mental health and suicide risk. Lancet Psychiatry 2014, 1, 86-94. [CrossRef]

33. Hernandez-De-Menendez, M.; Díaz, C.A.E.; Morales-Menendez, R. Educational experiences with Generation Z. Int. J. Interact. Des. Manuf. (IJIDeM) 2020, 14, 847-859. [CrossRef] 
34. Cornell, D.G. Threat assessment as a school violence prevention strategy. Criminol. Public Policy 2020, 19, 235-252. [CrossRef]

35. Eisenbraun, K.D. Violence in schools: Prevalence, prediction, and prevention. Aggress. Violent Behav. 2007, 12, 459-469. [CrossRef]

Publisher's Note: MDPI stays neutral with regard to jurisdictional claims in published maps and institutional affiliations.

(C) 2020 by the authors. Licensee MDPI, Basel, Switzerland. This article is an open access article distributed under the terms and conditions of the Creative Commons Attribution (CC BY) license (http://creativecommons.org/licenses/by/4.0/). 